\title{
SEA TURTLE CONSERVATION: INTERVIEW
}

\author{
Transforming Cultures eJournal, \\ Vol. 5 No 1 June 2010 \\ http://epress.lib.uts.edu.au/journals/TfC
}

\section{Kartik Shanker}

\begin{abstract}
Kartik Shanker is a biologist at the Centre for Ecological Studies, Indian Institute of Science, Bangalore. He has published on sea turtle biology and marine conservation and is the immediate past President of the International Sea Turtle Society. He edits the journal Conservation and Society, based in India and offering analyses of global conservation politics and ecology which foreground the perspectives of the global South. This journal focuses on communication not only between researchers and advocates working in the ecological sciences and in social science and humanities, but in fostering communication between academic researchers on the one hand and community and NGO audiences on the other.

This interview was conducted by Nick McClean during Kartik's visit to Sydney for the Cities Nature Justice conference, held 10 - 12 December, 2008, at the University of Technology Sydney. Nick McClean is currently undertaking PhD research at ANU on comparative approaches to conservation in Australia and India.
\end{abstract}

Kartik I live and work in Bangalore, but I was born in Chennai, formerly known as Madras in Tamil Nadu, in the south east of India. My early work was with a group known as the Student Sea Turtle Conservation Network and today I think it is one of the flagships for sea turtle conservation in India. I owe the origins of my work today to my interest in sea turtles, and so to this group as well.

Nick: Can you tell me a bit about the turtles around southern India?

Kartik Sea turtles are generally fairly easy to summarise. There are a total of 
seven species, of which five are globally distributed. The only two that are not globally distributed are the Kemp's Ridley, which is found on the Atlantic coast of Mexico and the Flat Back Turtle, found on the northern coast of Australia. The other five, the loggerhead, eatherback, olive ridley, green and hawksbill turtles are pretty much found everywhere. We have all of these species in India, mostly in the offshore islands, that's the Andaman and Nicobar Islands in the Bay of Bengal, east of southern India and of Sri Lanka. On the mainland coast of southern India, at least in the last three decades, we've only had olive ridley turtles. High densities on the east coast, low densities on the west coast, but pretty much everywhere there's a sandy beach, there are some olive ridleys nesting at some point of time in the year. The best known of these nesting areas is in Orissa, a state north of Tamil Nadu, which has one of the three mass nesting rookeries worldwide.

Mass nesting of olive ridleys takes place either during a particular season or through the year, as in Mexico and Costa Rico for example. Essentially, in the span of three or four nights, you get anywhere between ten thousand and a hundred thousand turtles nesting simultaneously. Orissa is one of the better-known sites worldwide and has been a centre of both research and conservation. On the Indian east coast, nesting usually occurs between December and March, which is winter, and the turtles are believed to come from further down along the coast, essentially from Sri Lanka. There's an area as the Gulf of Mannar between Sri Lanka and India where a lot of green and olive ridley turtles are known to feed, so at least some of the turtles that nest in Orissa come from that region. Recent telemetry studies are showing that they could be coming from elsewhere in the Indian Ocean but some of them seem actually to be resident off shore from Orissa itself. During the nesting season, they usually stay within four or five kilometres, but after the nesting season they seem to travel further afield, from 50 to even 100 kilometres off shore. However, they don't seem to be going further south, into the Indian Ocean, as at one time we believed that all of them did.

Now the Leatherback turtle is quite different, and its most notable for its deep diving ability. Its average dives are perhaps not more than a hundred, or even a couple of hundred metres, but it's been recorded to dive up to a thousand metres. The dives are physiologically astonishing for a reptile, but equally astonishing is the fact that they foray into sub Arctic waters; most people would imagine reptiles to be cold blooded, 
which essentially means that their body temperature varies with the environment. Leatherbacks, however, when they swim in these colder waters, are able to maintain their body temperature at about 10 to 15 degrees above the surrounding temperature. So in some sense, they're actually thermo-regulating, the way that scientists today believe that some dinosaurs did. In fact, some of the clues about how large reptiles may have dealt with the environment come from studying species such as leatherbacks. The other really interesting thing about sea turtles is that the sex of the offspring is determined by the temperature of incubation, as it is for crocodiles. So this has suggested one interesting theory, which might not be true, about the extinction of dinosaurs, which is that it might actually have come about by a very small change in surrounding temperature.

Nick: $\quad$ You mention that at some times, these turtles can nest up to 100,000 turtles on one beach at a time. What's the scene like, and the feeling like, when you're walking through this mass breeding?

Kartik I dreamed about it from the day I read about turtles for the first time in the 1980s, and this was about the same species that we worked on in Madras. When we started, we'd walk for days on end without seeing a single adult female. The first year that I was on the beach, I walked for two months and never saw nesting turtle at all. So, growing up in Madras, our feeling on seeing a single adult female was one of awe and wonder.

Ten years later, I finally got to work in Orissa but I was actually at the wrong nesting site when the mass nesting began in Gahirmatha in the north of Orissa. Gahirmatha is this little island in a sanctuary along the delta of one of the rivers, with a beautiful mangrove forest called Bhitarkanika, and the nesting takes place on these offshore sandbars. So I rushed through an entire day and an entire night to get to the right site, spent several hours on a boat, got to the island and went to the nesting beach. As we came over this little hill - a really small sand bar, probably only 100 metres across, so basically just walking over the dune at one end - and it was just a sea of turtles on the beach.

They were all over the beach, crawling over each other, crawling into one another, with 
the moonlight glistening off their backs, sand flying in the air. At some point of time, there were eggs flying through the air because they're all digging up each other's nests! Its an utter and absolute manic frenzy! And what's really astonishing is that under normal circumstances these turtles are really skittish, so if you walked up to them before they started nesting, they'd turn around and go back into the sea. They sometimes dig two or three nest holes before they're happy with one. But during a mass nesting, which is sort of popularly known as an arribadas, which means 'arrival' in Spanish, during the arribadas, they just want to come onshore and dump their eggs. So, sometimes you see turtles dropping their eggs without fully digging their nest, trailing eggs along the ground. Its complete turtle lunacy!

What's quite remarkable about the density of some of these nesting events becomes evident later on. We went back to the beach two months later, just before the hatching was due to occur. They hatch over a period of two or three days, and just before the hatchlings come out, they start moving around, so the sand actually collapses on top of the nest. If you put your foot on top of a nest that's hatched, your foot will go right into the ground because of the loose sand. So we were trying to walk across this beach, and pretty much everywhere, every single spot that you put a foot on, your foot would sink into the ground. At some point, we realised we weren't actually going to be able to walk across the beach, so we walked all the way around it to get to the other side. Pretty much the entire sand bar was chock full of turtle eggs. So the mass hatching is as spectacular a phenomenon as the mass nesting, because 100,000 nests might produce about 100 hatchlings per nest, which is about 10 million hatchlings. They're all going to be crawling out over a four or five day period. So it's all one of nature's extravaganzas! Very few of those hatchlings actually survive. Sometimes, entire mass nesting events are washed away by a tide, but obviously, this works in evolutionary time. They are the smallest of the sea turtles, and they're highly subjected to predation, so it's quite likely that they figured out the only way that they'll get a few of their hatchlings to survive is to get together and nest all at once.

The Madras story in itself is fascinating in many respects. We came into it in the late '80's, when I went to college in Madras, and a group of us became interested in sea turtle conservation on the Madras coast. The movement had started on that coast about 15 years before. Interestingly enough, this was initiated by an American who'd moved 
to India, Romulus Whittaker, who became very well known as a snake conservationist. He and a small group, who were basically his friends, had started working along the Madras coast in the early 1970s, collecting turtle eggs and protecting them in a hatchery. Then the forest department had taken over the running of these hatcheries from the NGO that was doing it before and they were assisted by the Worldwide Fund for Nature in that the WWF would bring the volunteers to the beach, and the volunteers would go on this walk at night, and they would collect the eggs and take them to the forest department hatchery. In the late 1980s, the State Forest Department decided to stop and so a group of us doing our undergraduate degrees, decided that this was something that the students might be able to contribute to.

Olive ridley turtles are protected under the Indian Wildlife Protection Act, so you're not actually allowed to touch the turtles or the eggs without Government permission. In 1988, when the Government decided to shut down the program, we offered to run the hatcheries for them, but we had to get permission from the central Government in Delhi and this turned out to be an extremely tedious process. I think we did get permits for one year, but in subsequent years, what has happened both in Madras as well as in the other programs, is that the local groups work out an arrangement with the local forest department office, and essentially have to persuade them that what they're doing is for the good of the turtle, and work under a kind of informal arrangement. What it actually involved was setting up a large fenced area on the beach, building a hut for us to sleep in, all of which we did in the first year with, I think, what would the equivalent of about a hundred Australian dollars, and then, we would walk about 10 to 20 kilometres of beach every night within the city limits, nine at night till about one or two in the morning, and collect whatever eggs we found on the beach, and take them down to the hatchery, dig a nest over there, as much as possible like the turtle did, put the eggs in, cover it up, and take down data about clutch size and other parameters.

We actually got up the next morning and went to college, went to class. We probably slept through most of them, but we had to be physically present. And we did this over a three or four month period between December and March, and once the eggs in the nests started hatching, we'd then go down to the hatchery and collect the hatchlings as they came out of the nests and release them into the sea.

Initially, I think, we'd expected to do it for a year or two, and we did, carrying out the 
sea turtle work for a year or two and then moving on to jobs, higher education and other things. The group, however, still continues to do turtle conservation on the Madras coast today. Each year that goes by, this surprises me no end because over this 20 year period, there have been at least 6 or 7 major transitions of individuals. Every two or three years, someone completely new picks up the pieces and says, 'I'll do this because I think it's really important to do.'

More recently, another group has started doing a very similar kind of a program with fishing youth from the villages along the same coast, and this group does exactly the same thing. They have a much smaller hatchery, but one hatchery for each village, and the fishing youth of that village patrol the areas around their village and collect any eggs that need to be protected, and put them in their hatchery. So there's about 15 or 20 kilometres of that coast that gets a lot of conservation attention. As a biologist, I'm not sure it makes a difference to the population, but it certainly raises awareness about sea turtle conservation issues.

Nick: And so these people living in these fishing villages, have they traditionally harvested turtle eggs? What's their relationship to turtles, are they somehow dependent on them?

Kartik Along the Madras coast, there used to be collection of eggs, but this was not by the fishing communities. A number of the Hindu fishing communities along pretty much all of the Indian coast worshipped turtles as part of their religious beliefs. There were other nomadic communities that lived just away from the coast, who would come out to the beach during the turtle nesting season and collect the turtle eggs. In the first few years we were always in competition with this one really old man who somehow always seemed to beat us to the nests. What was a little worrying, during the first few years of our work, was that somehow the younger members of the fishing community felt less constrained by tradition. . While they would not go out looking for nests, if they were out at night and they came across one, they'd collect it and then pass it on to somebody who'd sell it in the market. Or they'd consume it within the village. This trend appeared to be increasing about 15 years ago, but with increasing awareness programs, its not really too much of an issue now. What has been an issue along most of the east coast is the taking of eggs by feral dogs, and feral animals of various sorts. 
Then there is the incidental mortality of adult turtles, particularly females, in trawl fishing nets. In Orissa that has resulted in probably ten to fifteen thousand turtles washing up dead, every year, on that coast over the last ten or twelve years. And that's only the number that wash up dead. We don't know the number that are actually being killed. The states further south also see dead turtles washed up, in at least the hundreds if not the thousands. That (the incidental mortality of turtles in trawl nets) has been the biggest source of mortality for sea turtles. There are a couple of traditional turtle fishing area in the south of Tamil Nadu, the southern-most state, which is adjacent to Sri Lanka. Both the Sri Lankan Tamils as well as the Tamils that live in India have fished for sea turtles, at least for decades, perhaps much longer, we don't really know. There are actually historical records of some of those fisheries dating back even to Roman times, in the case, for example, of the trade of hawksbill shells from Sri Lanka to the Roman empire. So we are not sure where the fishery took place, who was involved, or whether it's changed over time. All that is unclear but it's certainly an old fishery.

Nick: In that context of people having a range of relationships with turtles from the spiritual to a subsistence or harvesting arrangement, has the idea of conserving turtles met with some resistance in local communities? What's been your experience of community based conservation and initiatives?

Kartik Most of the conservation projects that we've encountered, to this point, work predominantly with communities that have not actually harvested adult turtles, although, on the west coast especially, there's fairly widespread take of eggs. So the local conservation groups that have worked with those communities have tried to reduce the take of the eggs through increased monitoring and increased education and awareness, rather than attempting to impose local bans. My impression is that there probably is some continued take of eggs, but there hasn't been a clear and strong resistance to conservation itself.

However, there has been a strong resistance to conservation in Orissa. Because Orissa is such a well-known and important nesting site, it's attracted a lot of international attention from big NGOs. So it has felt the impacts of international policy, and of large national NGOs, with huge amounts of conservation funding. It has reached a point 
where turtles have become a political symbol. There, both the trawler owners as well as traditional fishermen have resisted conservation efforts. Trawler owners have done so because they've been pinned up as the biggest killers of turtles (as by-catch in their trawl nets) and so they've vehemently objected to being painted as the villains of the piece. The traditional fishermen come with an even more complex story. They have faced zoning regulations that have impacted on their rights of use and rights of access to fishing areas, so they also feel that, to some extent, turtle conservation measures have impacted on their livelihoods. Its ironic because some of the earliest fishing laws were actually instituted to protect artisanal fishing from mechanised fishing. In the 1990s, conservationists had started citing these laws in the name of turtle protection. They said, basically, in a lot of media pieces, that if you implement these laws, turtles will be protected and so they started attacking the Government for not instituting these laws. So, strangely enough, although these laws should have protected artisanal fishermen, the fishermen started identifying turtle protection as an anti-people initiative. Its all become a complex and fuzzy, but what's happened in Orissa as a consequence of the politicisation of the debate is that fishermen generally tend to see turtle conservationists as anti-people people.

Nick: One of the interesting things that has come up in the discussions in the conference today, is the issue of Western ideas - not simply about conservation, but about change in general, and the interaction with people in non-Western countries. Its interesting because you, as a conservationist, as someone trained in conservation biology, obviously have a strong personal investment in seeing conservation happen. But, as someone from India, you may have opinions about who drives that or how it actually works out on the ground. Do you have a personal point of view on those issues?

Kartik Well, there are two separate questions over there. One of them pertains to conservation biology, which, I'd have to say, I'm sceptical about as a discipline, mainly because I think conservation on the ground is so little about biology and so much about politics, which biologists are, admittedly, poor at. So, in that sense, I'm not really sure what kind of impact 'conservation biology' makes. I myself have been involved for the last decade with turtle biology in Orissa, I've done marine turtle genetics, I've done telemetry, I've done population monitoring, and I'd have to say that I think very little of 
that knowledge has actually been useful.

But, there's a larger question in terms of whose ideas of conservation are being implemented on the ground, and increasingly, I think that a number of sociologists, anthropologists and people who work with human rights issues are raising these questions about, you know, perspectives of, and notions of, wildness and biodiversity and approaches to conservation. What is seen as being implemented in a number of these areas is either a Western notion or a Western notion that's currently being globalised, perhaps through some of the large international, the multi-national conservation organisations.

Not as a conservation biologist, but just as a conservationist, I'd have to agree with that notion largely. Where I think I'd qualify that is that it's not just a Western notion, or rather, the Western notion is not confined to the West. The Western ideas and the notions of Western culture have spread over the last century to other parts of the world and have spread extensively through India because we were colonised for 200 years. American culture has spread widely now too, because we're an English speaking country. So I would say that anybody in urban India already possesses a Western notion. And in a sense, I'd say that it's more of an urbanisation of conservation than a globalisation of conservation. I think it's not ideas that are coming in, physically, from the West, but instead it is ideas which are actually coming out of centres of learning in big cities, which is what I believe does happen in India today. I think that fights over large charismatic species such as turtles and elephants, fights over national parks and sanctuaries between all different kinds of conservationists, essentially occur between, as Amita Baviskar has pointed out at this conference, between folks from upper middle classes in cities, on both sides of the debate. The people who seem to have the strongest voices about turtle conservation, whether it's in Madras or whether it's on a remote beach in Orissa, seem to be people who were born and brought up in Bombay or Delhi or Chennai.

So in that sense, even within India, I think there are deep divisions between who speaks for conservation and whose notion of wildlife and whose notion of biodiversity it is. These are issues that some of us are trying to raise. The exclusive and probably very elite notions of biodiversity and conservation are not the only notions that are out there. 
We need to start engaging with the others, especially if we are to have any kind of long term success at all. I think the frustration that many wildlife conservationists feel is due to prolonged attempts to impose their ideas and their ideals on a community that's coming to it from a completely different angle and, ironically, often with a much much deeper connection to nature than the conservation activists have ever had.

Nick: $\quad$ Kartik Shanker, thank you very much for your time.

Kartik Thank you. 